https://doi.org/10.1093/pm/pnz148)

Classism in pain care:

The role of patient socioeconomic status on nurses' pain assessment and management practices.

Tânia Brandão $\mathrm{PhD}^{1}$, Lúcia Campos $\mathrm{Ms}^{2}$, Lies de Ruddere $\mathrm{PhD}^{3}$, Liesbet Goubert $\mathrm{PhD}^{3}$, Sónia F. Bernardes $\mathrm{PhD}^{2}$

${ }^{1}$ CIP, Departamento de Psicologia, Universidade Autónoma de Lisboa, Portugal

${ }^{2}$ ISCTE-Instituto Universitário de Lisboa (ISCTE-IUL), Centro de Investigação e Intervenção Social (CIS-IUL), Lisboa, Portugal

${ }^{3}$ Department of Experimental-Clinical and Health Psychology, Ghent University, Belgium

Funding: This work was supported by the Fundação para a Ciência e Tecnologia (FCT-Portugal) (grant number: PTDC/MHC-PSC/2041/2014; Principal Investigator: Sónia Bernardes).

Corresponding author: Sónia F. Bernardes; Edifício ISCTE-IUL, Av. das Forças Armadas, 36, cacifo 34 AA, 1649-026 Lisbon, Portugal; Tm: + 35121 7903210; E-mail: sonia.bernardes@iscte-iul.pt URL: https://ciencia.iscte-iul.pt/authors/sonia-gomes-da-costa-figueira-bernardes/cv 

https://doi.org/10.1093/pm/pnz148)

\begin{abstract}
Objective: Research on social disparities in pain care has been mainly focused on the role of race/racism and sex/sexism. Classism in pain assessment and management practices has been much less investigated. We aimed to test the effect of patient socioeconomic status (SES; a proxy of social class) on nurses' pain assessment and management practices and whether patient SES modulated the effects of patient distress and evidence of pathology on such practices.
\end{abstract}

Design: Two experimental studies with a 2 (patient SES: low/high) by 2 (patient distress or evidence of pathology: absent/present) between-subject design.

Subjects: Female nurses participated in two experimental studies $(n=150 / n=158)$.

Methods: Nurses were presented with a vignette/picture depicting the clinical case of a female with chronic low-back pain, followed by a video of the patient performing a pain inducing movement. Afterwards, nurses reported their pain assessment and management practices.

Results: The low SES patient's pain was assessed as less intense, more attributed to psychological factors and considered less credible (in the presence of distress cues) than the higher SES patient's pain. Higher SES buffered the detrimental impact of the presence of distress cues on pain assessment. No effects were found on management practices.

Conclusions: Our findings point to the potential buffering role of SES against the detrimental effect of certain clinical cues on pain assessments. This study contributes to raise the need to further investigate the role of SES/social class on pain care and its underlying meanings and processes.

Key-words: classism; socioeconomic status; pain assessment and management biases; diagnostic evidence of pathology; patient distress 
https://doi.org/10.1093/pm/pnz148)

\section{Classism in pain care: The role of patient socioeconomic status on nurses' pain assessment and management practices.}

\section{Introduction}

Research on social disparities in pain care has been mainly focused on the role of race/racism $(1,2)$ and sex/sexism in health-care professionals' assessment and management practices (3-5). Classism in pain care, however, has been given much less attention. Like racism and sexism, classism operates through social categorization and stereotyping, i.e., it implies the use of socially constructed and widely shared belief-systems about individuals once they are categorized according to their socioeconomic status (SES) $(6,7)$. This paper generally contributes with novel empirical evidence on the role of patient SES/classism in pain care.

Evidence on the effects of patient SES/classism in pain assessment and management is not only scarce but inconsistent. On the one hand, some studies show evidence of classism in pain care. Physicians hold negative attitudes towards low SES patients, who were perceived as demanding and less competent to self-manage pain or follow a multi-disciplinary treatment (8). Medical students, in an emergency medicine simulation, were less likely to ask about pain control and more likely to touch a low SES patient (9). Also, low SES has been associated with less frequent opioid and non-pharmacological treatment prescriptions, greater prescription of generic pain medication and an increased recognition of the importance of psychoeducation (810). On the other hand, a set of vignette studies using a novel social class implicit association test did not find significant effects of patient SES nor of implicit class biases on medical students', nurses' or physicians' pain assessment and management decisions (11-14). These inconsistent findings call for further investigation of the direct effects of patient SES on health- 

https://doi.org/10.1093/pm/pnz148)

care professionals' assessment and management practices. This was indeed the first aim of this study. As nurses play a pivotal role in pain care, given their more frequent and closest contact with patients and their role of intermediaries between patients and other members of multidisciplinary teams $(15,16)$ it was our specific aim to investigate the direct effects of patient SES on nurses' pain assessment and management practices.

Our second aim was to investigate whether patient SES modulated the effects of relevant clinical cues on pain assessment and management practices. Among all contextual cues that may influence pain care, patient distress - i.e., signs of emotional/psychological suffering brought on by pain (17) - and diagnostic evidence of pathology - i.e., confirmation, through complementary diagnostic tests, of a pathology or lesion that induces pain (18) - are ones most studied; pain is often under-assessed/treated in the presence (vs. absence) of patient distress $(17,18)$ or in the absence (vs. presence) of evidence of pathology 17,18$)$. The detrimental effects of these variables on nurses' pain assessments have been found in experimental vignette-based studies (e.g.,3,4) and studies conducted in real clinical contexts (e.g.,19,20). However, it is yet unknown whether the effects of those clinical cues are identical for high versus low SES patients. A well-documented phenomenon in social psychology shows that perceptions of members of lower social status groups are often more dependent on contextual cues than perceptions of members of higher social status groups (21). In other words, this would suggest that higher SES patients would be more immune to the detrimental impact of clinical cues such as the presence of distress or absence of evidence of pathology on the way their pain is assessed and treated. This contention, however, has never been directly tested. Thus, this paper specifically aimed to test the moderating effects of patient SES on the impact of patient distress and diagnostic evidence of pathology on nurses' pain assessment and management practices. 

https://doi.org/10.1093/pm/pnz148)

To accomplish these aims, two independent experimental studies were conducted in which patient SES and patient distress (study 1) or evidence of pathology (study 2) were manipulated to assess their effects on nurses' pain assessment and management practices. We hypothesised that: (H1) the pain presented by a lower SES patient would be underassessed/managed as compared to the pain presented by a higher SES patient; (H2) pain in the presence of distress/absence of evidence of pathology would be under-assessed/managed as compared to pain in the absence of distress/presence of evidence of pathology, and that this effect would be stronger for low SES patients.

\section{Study 1 - Methods}

\section{Participants}

Based on a priori power analysis for a 2 X 2 factorial ANOVA conducted with G*Power software (version 3.1.9.2), the desired sample size was set at 128 , in order to have a sufficient sample size using an alpha of 0.05 , a power of 0.80 , to detect at least medium effect sizes $(\mathrm{f}=$ 0.25) (22). Participants were recruited through the Internet between June and December 2017. In order to control for confounds between nurse and patient sex, and because there is a higher prevalence of female patients with chronic pain (23-25), only female nurses and nursing students were included in this study. Eighty-four nurses were not included because they did not provide any sociodemographic information.

One hundred and fifty Portuguese female nurses (83.56\%) and nursing students $(16.44 \%)$, aged 18-63 $(M=31.67 ; S D=10.26)$, participated in this study. Nurses had several clinical specialties and had between 1 month to 35 years of professional experience $(M=8.51$; $S D=9.99)$. Around $39 \%$ of the nurses $(\mathrm{n}=58)$ reported working or having worked in an emergency department, and $68 \%(n=102)$ were working or had worked with patients with 

https://doi.org/10.1093/pm/pnz148)

chronic pain. Almost $38 \%$ of the participants reported suffering $(n=36)$ or having suffered $(n$ =19) constant or intermittent pain for more than 3 months, with an average intensity of 5.36 out of $10(S D=1.92)$. Additionally, $78 \%(\mathrm{n}=117)$ of the participants reported having or having had contact with people suffering from chronic pain outside of their professional context.

\section{Experimental Design}

This study consisted of a 2 (patient SES: low vs. high) X 2 (patient distress cues: absent vs. present) between-subjects design. Participants were randomly assigned to one of the four experimental conditions.

\section{Independent variables}

Four written vignettes depicting a white female patient with chronic low back pain were used to manipulate patient SES and distress cues. Each participant was shown one picture of a female patient accompanied by a written vignette and one video sequence of that patient performing a pain-inducing activity (i.e., lying down on a bed and standing up). The picture and the video sequence were selected from the Ghent Pain Videos of Daily Activities (GPAVIDA) (26,27). For the purpose of this study, a pretested picture/video of a woman perceived as middle-aged, with normal weight, depicting a moderate level of pain behavior was chosen. Pretests also showed that this woman was perceived as ambiguous in terms of social status, i.e., she could be perceived as either having a low or a moderate/high SES, hence, guaranteeing the ecological validity of our SES manipulation. Patient SES was manipulated by level of education and occupational activity (28).

Vignettes were adapted from previous studies conducted with nurses $(3,29)$. Below is a sample vignette, including the alternative wording (in bold and parentheses) used to manipulate 
https://doi.org/10.1093/pm/pnz148)

each one of the independent variables (identified in square brackets) and the information held constant across experimental conditions.

This 45-year-old woman is married, completed the $9^{\text {th }}$ grade (a doctoral degree) and is a factory worker (judge). [Patient SES manipulation]. She goes to an emergency room complaining of lowback pain, with which she claims to have been living for more than 4 months.

In the waiting room, this woman is agitated and anxious (calm and quiet). Besides a painful facial expression, this woman is complaining and verbalizing her pain frequently and spontaneously (does not complain nor spontaneously verbalizes her pain). [Distress cues manipulation].

When called to the triage, this woman refers she has been living with a constant and intense pain in the lower back that radiates to her right leg. She says that sometimes the pain is so intense she has trouble walking and sleeping, describing it as a frightening pain (a sharp pain). [Distress cues manipulation].

This woman has been taking paracetamol on her own initiative, despite not being able to get any relief.

In line with earlier studies $(3,29)$, four independent nurses checked for the credibility, realism, and rigor of the scenarios $(M$ age $=36.25 ; S D=5.12 ;$ M years of experience $=13.50$; $S D=7.85)$ 

https://doi.org/10.1093/pm/pnz148)

After seeing the picture and reading the vignette (but before seeing the video), participants were asked to recall specific details of the scenario, namely patient's age, education, profession, pain duration, SES and distress cues. Perceived patient SES was assessed with the MacArthur Scale of Subjective Social Status (30). This scale presents a "social ladder" with 10 steps and participants were asked to place an X on the step on which they felt the woman stood. A four-item scale was used to measure participants' evaluation of distress cues (e.g., "To what extent is this woman expressing anxiety"; $\alpha=.79)(3,4)$. The SES and distress scales allowed us to assess whether the independent variables (patient SES and distress cues) were successfully manipulated.

\section{Dependent variables}

Pain assessment. Two independent 11-point numerical rating scales, ranging from 0 (no pain at all) to 10 (worst possible pain), were used to assess pain intensity during movement and overall pain intensity. One of the numerical rating scales was used immediately after nurses observed the video of the patient performing a pain-inducing activity, as to assess their ratings of pain intensity during movement (e.g., "How do you rate this woman's pain intensity while she is performing this movement?"). The other numerical rating scale was used to assess nurses' ratings of the overall pain intensity generally felt by the patient after considering all the information presented in the clinical scenario (e.g., "Considering all the information you have available about this clinical case, overall, how do you assess this women's pain intensity?"). Eleven-point numerical rating scales have been recommended as one of the most appropriate way to assess pain intensity (31).

Furthermore, based on previously validated scales $(3,29)$ the following dimensions of pain judgments were assessed, each measured with two items ranging from 1 (not at all) to 7 

https://doi.org/10.1093/pm/pnz148)

(extremely): pain disability (e.g., "To which extent do you believe this pain interferes with this woman's family life?"; $\mathrm{r}_{\mathrm{sb}}=.78$ ), severity of clinical situation (e.g., "To which extent do you rate this patient's clinical situation as worrying?"; $\mathrm{r}_{\mathrm{sb}}=.86$ ), pain credibility (e.g., "To which extent do you believe this patient's pain is genuine?"; $\left.\mathrm{r}_{\mathrm{sb}}=.90\right)$, and psychological attributions (e.g., "To which extent do you believe this patient's pain is caused by emotional factors?”; $\mathrm{rsb}$ $=.89)$. Scores were obtained by calculating the average of the two items, with higher scores representing higher levels of pain disability, severity of clinical situation, pain credibility and more psychological attributions.

Pain management. A previously validated measure (32) was used to rate nurses' willingness to offer support to the pain patient. Four items measured nurses' willingness to offer instrumental support (e.g., "To which extent would you be willing to help this woman place herself in a position to relieve her pain?") and four items measured nurses' willingness to offer emotional support (e.g., "To which extent would you be willing to talk with this woman as to bring her some emotional comfort?"). All items were rated on a Likert-type scale ranging from 1 (not at all willing) to 7 (extremely willing). Cronbach's alpha was .78 for instrumental support and .91 for emotional support indicating good internal consistency. Scores for each dimension were obtained by calculating the average of the four items, with higher scores representing higher levels of willingness to offer instrumental or emotional support. Pain assessment and managements items are presented in Table 1.

Additionally, drawing upon the Manchester Triage system for Emergency Departments (33) the following question was asked ("Imagine that you will have to attribute one of the following colors to the patient, considering that your choice will determine the maximum time that she 

https://doi.org/10.1093/pm/pnz148)

will have to wait to be seen the medical team of the emergency department. Please, choose the color that you intend to attribute to this patient."), with a 5-point scale, represented by 5 colors as follows: 1 = blue: non-urgent (i.e., 240 minutes maximum waiting time), 2 = green: standard (i.e., 120 minutes maximum waiting time), 3 = yellow: urgent (i.e., 60 minutes maximum waiting time), 4 = orange: very urgent (i.e., 10 minutes maximum waiting time), $5=$ red: immediate (i.e., 0 minutes maximum waiting time). The higher the score the lower the waiting time, hence, higher the emergency.

\section{Procedure}

This study was approved by the Ethical Committee of the ISCTE - Lisbon University Institute (Reference: 12/2017). Data were collected using the online software program Qualtrics ${ }^{\circledR}$. Different nursing schools were contacted and asked to send a recruitment email to their post-graduate student mailing lists inviting them to participate in the study. Additionally, two public hospitals in Lisbon were contacted in order to share the online questionnaire among their nursing staff. The study was approved by the Boards of Directors and/or Ethical Committees of the participating institutions. The aims of the study were described in the landing page. Participants were invited to take part on a study supposedly on memory and decision-making processes in clinical contexts. Participants were told that the study aimed to understand how memory and decision-making processes would influence health-care professionals' judgments when facing a clinical scenario. Informed consent was required to proceed to the survey. Participants were randomly allocated to one of the four experimental conditions. First, participants saw the picture and read the associated vignette. Then, they were asked to recall several details of the clinical scenario in order to check the manipulations of the independent variables. Subsequently, participants saw the video and were asked to assess the 

https://doi.org/10.1093/pm/pnz148)

patient's pain and report their intentions to help the patient. Finally, sociodemographic and clinical data were collected, i.e., age, education, workplace, years of professional experience, previous professional experience in an emergency department and with patients with $\mathrm{CP}$ and personal and vicarious experience of $\mathrm{CP}$.

The time required to complete the protocol was on average 11 minutes. One $25 € \mathrm{gift}$ voucher was drawn at random among those who left their emails for being compensated for their participation. Also, participants were thanked, debriefed and the ones who were interested in knowing more about the study submitted their email address.

\section{Data analysis}

All analyses were performed using SPSS version 23.0 (SPSS, Inc., Chicago, IL, USA). Descriptive statistics were used to describe participants' sociodemographic and clinical data and summarize participants' responses. Independent sample t-tests were used to check the manipulation of independent variables (i.e., SES and distress cues). Participants who were not able to correctly recall patient's education, profession, pain duration and SES were excluded from the analyses. Pearson $(r)$ and Spearman $\left(r_{s}\right)$ correlations and t-tests were conducted to explore the associations between sociodemographic (e.g., age, years of professional experience, professional vs. student status) and clinical characteristics (e.g., personal and vicarious pain experiences) and pain assessment and management variables. Only age and years of professional experience were significantly correlated with psychological attributions $\left(r_{(128)}=.23, \mathrm{p}<.05\right.$ and $r_{(128)}=.22, \mathrm{p}<.05$, respectively). The same pattern was observed with the Manchester Triage variable $\left(\mathrm{r}_{\mathrm{s}(128)}=.24, p<.05\right.$ for age and $\mathrm{r}_{\mathrm{s}(128)}=.29, p<.01$ for years of professional experience). Because age and years of professional experience were 

https://doi.org/10.1093/pm/pnz148)

highly correlated $\left(\mathrm{r}_{(128)}=.95, \mathrm{p}<.01\right)$, we decided to use only age as a covariate in the analyses regarding psychological attributions and the Manchester Triage.

Correlations among the dependent variables were also analyzed. Significant correlations were found between pain intensity during movement and overall pain intensity ( $\mathrm{r}$ $\left.{ }_{(128)}=.88, p<.01\right)$, between pain disability and severity of the clinical situation $\left(\mathrm{r}_{(128)}=.72, p\right.$ $<.01)$, and between instrumental support and emotional support $\left(\mathrm{r}_{(124)}=.62, p<.01\right)$. Given these results, three multivariate analysis of variance (MANOVAs) were conducted for analyzing the main and interaction effects of SES and distress on these three sets of variables. A two-way analysis of variance (ANOVA) was conducted over pain credibility. Two two-way analysis of covariance (ANCOVA) were conducted over psychological attributions and the Manchester Triage Score, respectively, controlling for age. Post-hoc simple effect analyses were used to decompose the significant interaction effects. A significance level of .05 was assumed for all analyses.

\section{Results}

Manipulation check

Of the 150 participants, 22 were excluded from the analyses because they failed the manipulation checks. Specifically, ten participants were excluded because they recalled the patient's pain as acute (pain felt for less than four hours or four days), and 12 failed to perceive patient SES as low or high according to the scenario presented. Thus, 128 participants were included in the analyses. No socio-demographic differences were found between included and excluded participants based on the SES manipulation check.

Analyses showed that the manipulations worked: significant differences were found between the two conditions in perceived SES $\left(t_{(126)}=-24.78, p<.01 ; M_{\text {LowSES }}=3.94 ; \mathrm{SD}=\right.$ 
https://doi.org/10.1093/pm/pnz148)

.94 ; vs. $\left.M_{\mathrm{HighSES}}=8.23 ; S D=1.01\right)$, as well as in patient distress perceptions $\left(t_{(124)}=-15.13, p\right.$ $<.01 ; M_{\text {absent }}=2.41 ; S D=.78 ;$ vs. $\left.M_{\text {present }}=4.45 ; S D=.73\right)$.

\section{SES main effects on pain assessment and management practices}

A borderline multivariate main effect of patient SES on pain intensity ratings was found $\left(F(2,123)=2.83, p=0.06\right.$, eta $\left.^{2}=.04\right)$; univariate tests (Table 1$)$ showed a significant main effect of patient SES upon estimated overall pain intensity and a marginally significant effect of patient SES upon estimated pain intensity during movement. Overall, the higher SES patient was perceived as having more intense pain than the lower SES patient. A main effect of patient SES on psychological attributions was also found. The lower SES patient's pain was more attributed to psychological factors than the higher SES patient's pain.

No significant main effects were found of patient SES on nurses' judgements of pain disability, severity of clinical situation and credibility or on their intentions of offering support to the patient and attribution of waiting time (Manchester Triage). 
https://doi.org/10.1093/pm/pnz148)

Table 1

Main and interaction univariate effects of patient socioeconomic status and distress cues on pain assessment and management practices (study 1).

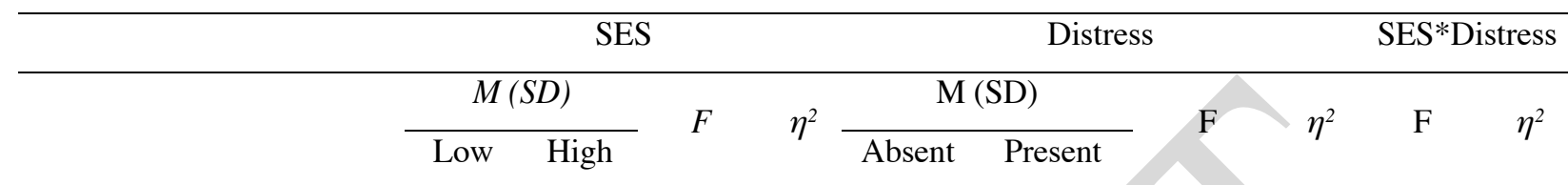

\section{Pain assessment}

\begin{tabular}{|c|c|c|c|c|c|c|c|c|c|c|}
\hline $\begin{array}{c}\text { Pain intensity on } \\
\text { movement }\end{array}$ & $\begin{array}{c}5.19 \\
(1.85)\end{array}$ & $\begin{array}{c}5.82 \\
(1.78)\end{array}$ & $3.75^{+}$ & .03 & $\begin{array}{c}5.63 \\
(1.92)\end{array}$ & $\begin{array}{l}5.34 \\
(1.75)\end{array}$ & .8 & .01 & .20 & .00 \\
\hline Overall pain intensity & $\begin{array}{c}5.49 \\
(1.80)\end{array}$ & $\begin{array}{r}6.22 \\
(1.67)\end{array}$ & $5.61 *$ & .04 & $\begin{array}{l}5.84 \\
(1.90)\end{array}$ & $\begin{array}{r}5.81 \\
(1.63)\end{array}$ & .02 & .00 & 67 & .01 \\
\hline Pain disability & $\begin{array}{l}5.01 \\
(.88)\end{array}$ & $\begin{array}{l}5.03 \\
(.86)\end{array}$ & & .00 & $\begin{array}{l}4.99 \\
(.87)\end{array}$ & $\begin{array}{l}5.05 \\
(.87)\end{array}$ & & .00 & .05 & .00 \\
\hline $\begin{array}{c}\text { Severity of clinical } \\
\text { situation }\end{array}$ & $\begin{array}{l}4.29 \\
(.86)\end{array}$ & $\begin{array}{l}4.32 \\
(.64)\end{array}$ & & .00 & $\begin{array}{l}4.26 \\
(.81)\end{array}$ & $\begin{array}{l}4.34 \\
(.71)\end{array}$ & .41 & .00 & .01 & .00 \\
\hline Pain credibility & $\begin{array}{l}4.99 \\
(.97)\end{array}$ & $\begin{array}{l}5.26 \\
(.94)\end{array}$ & 25 & .02 & $\begin{array}{l}5.21 \\
(.96)\end{array}$ & $\begin{array}{l}5.02 \\
(.96)\end{array}$ & 1.00 & .01 & $3.60^{\dagger}$ & .03 \\
\hline Psychological attributions & $\begin{array}{r}3.54 \\
(1.09)\end{array}$ & $\begin{array}{c}3.05 \\
(1.10)\end{array}$ & 6.88 & .05 & $\begin{array}{r}3.02 \\
(1.14)\end{array}$ & $\begin{array}{c}3.59 \\
(1.02)\end{array}$ & $7.66 * *$ & .06 & .00 & .00 \\
\hline \multicolumn{11}{|l|}{ Pain management } \\
\hline Instrumental support & & 5.43 & 2.71 & .02 & $\begin{array}{l}5.35 \\
(.91)\end{array}$ & $\begin{array}{c}5.21 \\
(1.00)\end{array}$ & .69 & .00 & 0.48 & .00 \\
\hline Emotional support & $\begin{array}{c}5.43 \\
(1.12)\end{array}$ & $\begin{array}{l}5.57 \\
(1.00)\end{array}$ & .47 & .00 & $\begin{array}{c}5.43 \\
(1.11)\end{array}$ & $\begin{array}{c}5.56 \\
(1.02)\end{array}$ & .64 & .01 & 2.35 & .02 \\
\hline
\end{tabular}

Note. ${ }^{*} p<.05 ; * * p=<.01 ; * * * p=<.001 ; \dagger=.06$

Main effects of patient distress cues on pain assessment and management practices

Results showed a significant main effect of patient distress cues on psychological attributions (Table 1), with nurses attributing more psychological factors to pain when in the 

https://doi.org/10.1093/pm/pnz148)

presence of distress cues than when such cues were absent. No significant main effects were found of patient distress cues on nurses' judgements of pain intensity, disability, severity of clinical situation and credibility, nor on their intentions of offering support to the patient and attribution of waiting time (Manchester Triage).

Interaction effects between SES and patient distress cues on pain assessment and management practices

A marginal interaction effect of patient SES and distress cues was found for pain credibility (Table 1). Figure 1 depicts the simple effect analysis. The low SES patient's pain was perceived as less credible than the high SES patient's pain, but only when distress cues were present. Also, pain in the presence of distress cues was judged as less credible than in the absence of distress cues, but only for the low SES patient.

\section{Conclusion}

Our findings showed that patient SES influenced some of nurses' pain assessments but not their management practices. Results partially confirmed our hypothesis 1 showing that nurses slightly underestimated low SES patient's pain as compared to the high SES patient's pain; more specifically, the former was perceived as feeling less intense pain than the latter and her pain was more attributed to psychological factors. Furthermore, as expected, and in line with previous studies $(4,17,18)$, the presence of distress cues leads to more psychological attributions to pain than the absence of distress cues. Our hypothesis 2 was also partially confirmed; pain in the presence of distress cues was perceived as less credible than pain in the absence of distress cues, but only for low SES patients. Moreover, it was only in the presence 
https://doi.org/10.1093/pm/pnz148)

of distress cues that the low SES patient's pain was perceived as less credible than the high SES patient's pain.

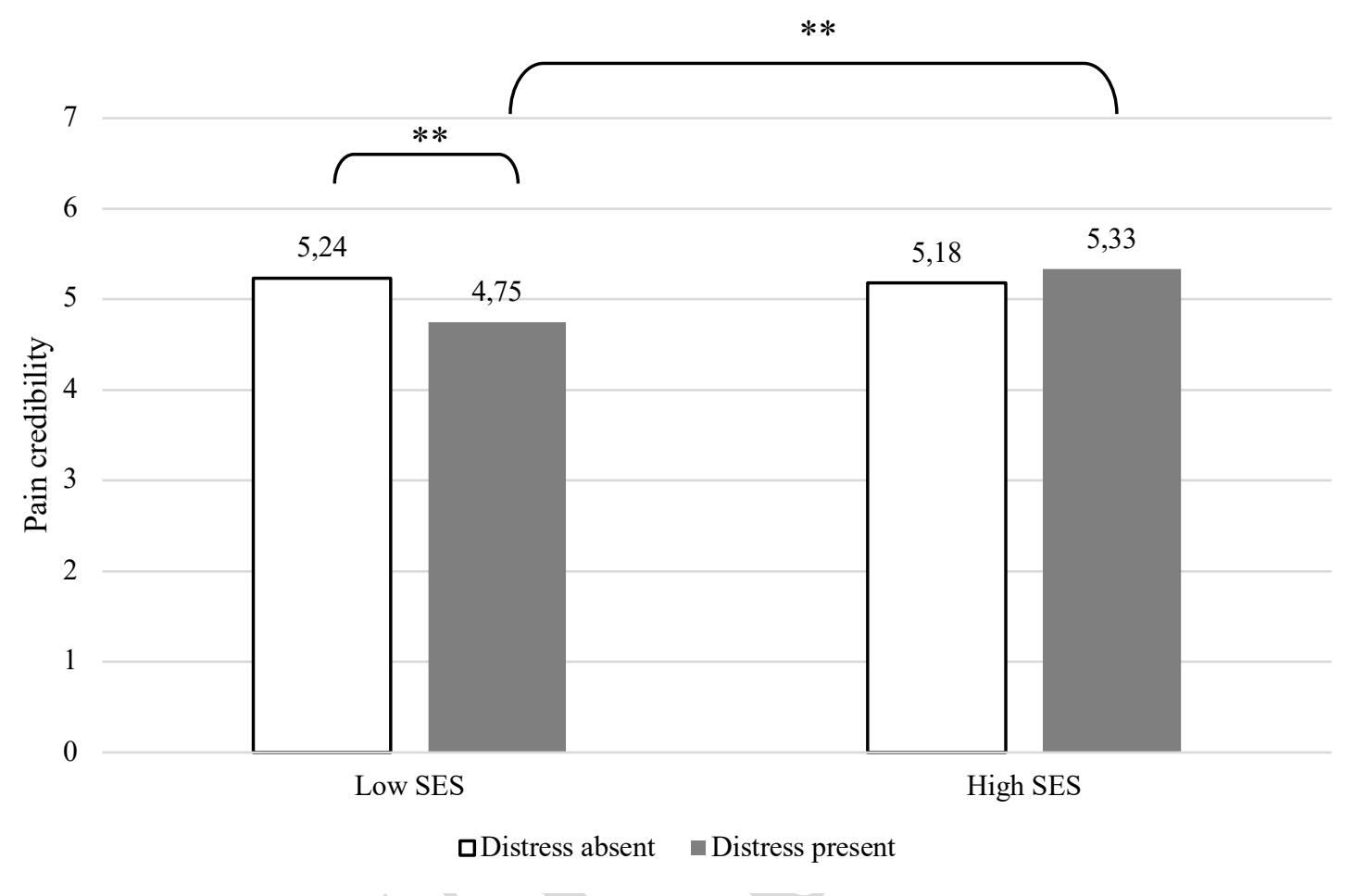

Note. ${ }^{*} p<.05 ; * * p=<.01 ; * * * p=<.001$

Figure 1. Interaction effect between patient SES and distress cues on pain credibility (Study 1).

\section{Study 2 - Methods}

\section{Participants}

Using an identical recruitment procedure as in Study 1, 271 new individuals participated in Study 2. Eighty-four participants were excluded as they did not provide any sociodemographic information, resulting in a final sample of 158 Portuguese female nurses $(65 \%)$ and nursing students $(35 \%)$, aged $18-64(M=28.43 ; S D=10.70)$. Nurses had several clinical specialties and had between 1 month to 42 years of professional experience $(M=10.70$; 
https://doi.org/10.1093/pm/pnz148)

$S D=10.56)$. Around $31 \%$ of the nurses $(n=49)$ reported working or having worked in an emergency department, and $56 \%(\mathrm{n}=88)$ stated working or having worked with patients with chronic pain. Almost $35 \%$ of the participants reported suffering $(n=33)$ or having suffered $(n$ $=21$ ) constant or intermittent pain for more than 3 months, with an average intensity of 5.5 out of $10(S D=1.76)$. Additionally, $83 \%$ of the participants reported having or having had contact with people suffering from chronic pain outside of their professional context.

\section{Experimental Design}

This study consisted of a 2 (patient SES: low vs. high) X 2 (Evidence of Pathology: absent vs. present) between-subjects design. Participants were randomly assigned to one of the four experimental conditions.

\section{Independent variables}

The procedures used to manipulate the independent variables were similar to the procedures described in Study 1. Below is a sample vignette, including the alternative wording (in bold and parentheses) used to manipulate each one of the independent variables (identified in square brackets) and the information held constant across experimental conditions.

This 45-year-old woman is married, completed the $9^{\text {th }}$ grade (a doctoral degree) and is a factory worker (judge). [Patient SES manipulation]. She goes to an emergency room complaining of lowback pain, with which she claims to have been living for more than 4 months. 

https://doi.org/10.1093/pm/pnz148)

This woman refers that she has been living with a constant and intense low-back pain radiating to her right lower limb. She says that sometimes pain is so intense that she has trouble walking and sleeping. She has been taking paracetamol on her own initiative for pain relief without success.

Recently, this woman had X-ray, CAT scan and MRI of the lumbar spine that showed significant evidences of a herniated disc (did not show any evidence of significant anomalies) [Evidence of pathology manipulation].

As in Study 1, participants were asked to recall information about patient's age, education, profession, pain duration, SES and presence of evidence of pathology as a manipulation check. As in the previous study, perceptions of patient SES were assessed with the MacArthur Scale of Subjective Social Status. To recall the presence or absence of evidence of pathology participants were asked whether the diagnostic test results (i.e., X-ray, CAT scan and MRI) showed/did not show evidences of significant anomalies of a herniated disc (yes-orno answer).

\section{Dependent variables}

Dependent variables were the same as in Study 1. For pain assessment measures, Spearman-Brown coefficient was .74 for pain disability, .78 for severity of the clinical situation, .72 for pain credibility and .86 for psychological attributions, indicating good internal consistencies for all dimensions. For pain management measures, Cronbach's alpha was .80 for instrumental support and .83 for emotional support, indicating good internal consistency. 
https://doi.org/10.1093/pm/pnz148)

\section{Procedure}

The procedure was identical to that of Study 1.

\section{Data analyses}

Data analysis procedures were similar to the ones described in Study 1. No significant associations were found between sociodemographic/clinical and dependent variables. As in the previous study, significant correlations were found between pain intensity during movement and overall pain intensity $\left(\mathrm{r}_{(124)}=.89, p<.001\right)$, between pain interference and severity of the clinical situation $\left(\mathrm{r}_{(124)}=.69, p<.001\right)$, and between intentions of providing instrumental support and emotional support $\left(\mathrm{r}_{(124)}=.55, p<.001\right)$. Given these results, three MANOVAs were conducted for analyzing the main effects of SES and evidence of pathology, and their interaction effect on these three sets of dependent variables. Three two-way analyses of variance (ANOVAS) were conducted over pain credibility, psychological attributions and the Manchester Triage score, respectively.

\section{Results}

\section{Manipulation check}

Of the 158 participants, 34 were excluded from the analyses because they failed the manipulation checks. Specifically, 13 participants were excluded because they identified the patient's pain as acute (pain felt less than four hours or four days), two failed to identify the patient's SES, and 19 failed to recall evidence of pathology. Thus, a total of 124 participants were included in the analyses. No socio-demographic differences were found between included and excluded participants, except for own experience of $\mathrm{CP}\left(X^{2}(1)=5.62, p<.05\right)$; there were 

https://doi.org/10.1093/pm/pnz148)

more individuals not reporting personal experience with CP among those who were excluded. SES manipulation was successful as there were significant differences in SES perception between the two conditions $\left(t_{(122)}=-20.21, p<.01 ; M_{\text {LowSES }}=4.33 ; S D=.98\right.$; vs. $M_{\mathrm{HighSES}}=$ $8.16 ; S D=1.12)$

Main effects of SES on pain assessment and management practices

A multivariate main effect of patient SES was found for pain intensity ratings $(F(2,119)$ $=3.51, p<.05$ eta $^{2}=.06$ ). Univariate analysis (Table 2 ) showed that the higher SES patient was perceived as having more intense pain than the lower SES patient in both overall and pain during movement intensity assessments. No significant main effects of SES were found upon participants' judgements of pain disability, severity of clinical situation, credibility, or intentions of offering support and on their attributions of patient waiting time (Manchester Triage).

Main effects of evidence of pathology on pain assessment and management practices

Results showed significant multivariate main effects of evidence of pathology on pain intensity $\left(F(2,119)=2.91, p=.059\right.$, eta $\left.^{2}=.05\right)$, pain disability and severity of clinical situation measures $\left(F(2,119)=3.06, p=.05\right.$, eta $\left.^{2}=.05\right)$, and intentions of offering support $(F(2,119)$ $=5.39, p<.01$ eta $\left.^{2}=.08\right)$. Univariate tests (Table 2 ) showed that in the absence of evidence of pathology, participants perceived the patient's pain as less intense overall and during movement, less disabling, the clinical situation as less severe, the pain was more attributed to psychological causes and they were less willing to offer instrumental support. No significant main effects of evidence of pathology were found on pain credibility judgements. 
https://doi.org/10.1093/pm/pnz148)

Interaction effects between SES and evidence of pathology on pain assessment and management practices

A borderline multivariate interaction effect between evidence of pathology and patient SES was found for pain intensity measures $\left(F(2,119)=2.75, p=.07\right.$, eta $\left.{ }^{2}=.04\right)$. Univariate tests (Table 2) showed that whereas the interaction for overall pain intensity was significant ( $p$ $<.01)$, the interaction for pain during movement was only marginally significant $(p=.07)$. Simple effect analyses showed the same pattern of results for both pain intensity ratings (see Figure 2). The high SES patient's pain was perceived as more intense than the low SES patient's pain, but only when evidence of pathology was present.

Table 2

Main and interaction univariate effects of patient socioeconomic status (SES) and evidence of pathology (EP) on pain assessment and management practices (study 2).

\begin{tabular}{|c|c|c|c|c|c|c|c|c|c|c|}
\hline & 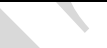 & SES & & & \multicolumn{4}{|c|}{$\mathrm{EP}$} & \multicolumn{2}{|c|}{ SES*EP } \\
\hline & \multicolumn{2}{|c|}{$M(S D)$} & & & \multicolumn{2}{|c|}{$\mathrm{M}(\mathrm{SD})$} & \multirow{2}{*}{$\mathrm{F}$} & \multirow{2}{*}{$\eta^{2}$} & \multirow{2}{*}{$\mathrm{F}$} & \multirow{2}{*}{$\eta^{2}$} \\
\hline & Low & High & & & Absent & Present & & & & \\
\hline \multicolumn{11}{|l|}{ Pain assessment } \\
\hline $\begin{array}{c}\text { Pain intensity on } \\
\text { movement }\end{array}$ & $\begin{array}{r}5.00 \\
(1.64)\end{array}$ & $\begin{array}{l}5.79 \\
(1.66)\end{array}$ & $7.08 *$ & .06 & $\begin{array}{r}5.05 \\
(1.59)\end{array}$ & $\begin{array}{c}5.73 \\
(1.73)\end{array}$ & $5.34 * *$ & .04 & 5.34* & .04 \\
\hline Overall pain intensity & $\begin{array}{l}5.31 \\
(1.44)\end{array}$ & $\begin{array}{c}5.97 \\
(1.69)\end{array}$ & $5.28 *$ & .04 & $\begin{array}{c}5.30 \\
(1.54)\end{array}$ & $\begin{array}{c}5.97 \\
(1.59)\end{array}$ & $5.63 *$ & .05 & $3.28 \dagger$ & .03 \\
\hline Pain disability & $\begin{array}{l}5.07 \\
(.74)\end{array}$ & $\begin{array}{l}5.02 \\
(.82)\end{array}$ & .19 & .00 & $\begin{array}{l}4.88 \\
(.81)\end{array}$ & $\begin{array}{l}5.21 \\
(.77)\end{array}$ & $5.56 *$ & .04 & 1.78 & .02 \\
\hline $\begin{array}{c}\text { Severity of clinical } \\
\text { situation }\end{array}$ & $\begin{array}{l}4.17 \\
(.68)\end{array}$ & $\begin{array}{l}4.25 \\
(.67)\end{array}$ & .36 & .00 & $\begin{array}{l}4.08 \\
(.69)\end{array}$ & $\begin{array}{l}4.34 \\
(.62)\end{array}$ & 4.78* & .04 & .145 & .00 \\
\hline Pain credibility & $\begin{array}{c}5.27 \\
(1.00)\end{array}$ & $\begin{array}{l}5.33 \\
(.95)\end{array}$ & .11 & .00 & $\begin{array}{c}5.16 \\
(1.04)\end{array}$ & $\begin{array}{l}5.44 \\
(.88)\end{array}$ & 2.54 & .02 & .05 & .00 \\
\hline Psychological attributions & $\begin{array}{l}3.20 \\
(.89)\end{array}$ & $\begin{array}{l}3.34 \\
(.94)\end{array}$ & .89 & .01 & $\begin{array}{l}3.51 \\
(.92)\end{array}$ & $\begin{array}{l}3.05 \\
(.88)\end{array}$ & $8.36 * *$ & .07 & .05 & .00 \\
\hline
\end{tabular}



https://doi.org/10.1093/pm/pnz148)

\begin{tabular}{|c|c|c|c|c|c|c|c|c|c|c|}
\hline \multicolumn{11}{|l|}{ Pain management } \\
\hline Instrumental support & $\begin{array}{l}5.18 \\
(.99)\end{array}$ & $\begin{array}{l}5.20 \\
(.84)\end{array}$ & .00 & .00 & $\begin{array}{l}5.01 \\
(.97)\end{array}$ & $\begin{array}{l}5.36 \\
(.83)\end{array}$ & $4.67 *$ & .04 & 1.66 & .01 \\
\hline Emotional support & $\begin{array}{l}5.40 \\
(.99)\end{array}$ & $\begin{array}{l}5.29 \\
(.99)\end{array}$ & .46 & .00 & $\begin{array}{c}5.41 \\
(1.03)\end{array}$ & $\begin{array}{l}5.28 \\
(.90)\end{array}$ & .64 & .01 & 2.29 & .02 \\
\hline
\end{tabular}

Note. ${ }^{*} p<.05 ; * * p=<.01 ; * * * p=<.001 ; \dagger=.07$

Also, pain in the presence of evidence of pathology was judged as more intense than in the absence of evidence of pathology, but only for the high SES patient. No significant interaction effects were found upon participants' judgements of pain disability, severity of the clinical situation, pain credibility, psychological attributions intentions of offering support and on their attributions of patient waiting time (Manchester Triage).

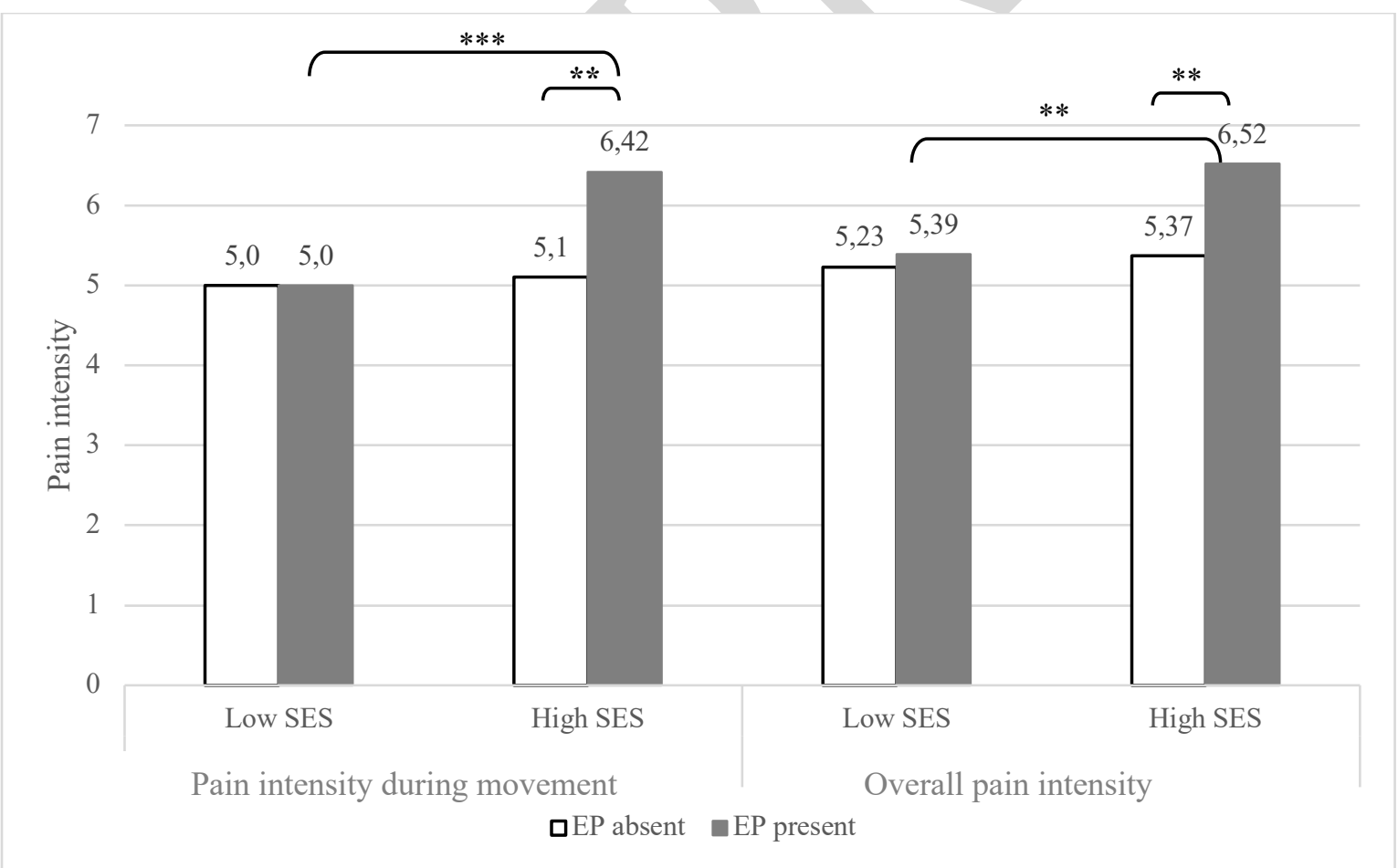

Note. ${ }^{*} p<.05 ; * * p=<.01 ; * * * p=<.001$

Figure 2. Interaction effect between patient SES and evidence of pathology (EP) on pain intensity ratings (Study 2). 

https://doi.org/10.1093/pm/pnz148)

\section{Conclusion}

As in Study 1, our results showed that patient SES influenced nurses' pain assessments but not their management practices. Partially supporting hypothesis 1, and replicating Study 1 findings, results showed that nurses perceived the higher SES patient as having slightly more intense pain than the lower SES patient. As expected, and in line with previous studies $(3,4,17,18,27)$, in the presence of evidence of pathology nurses judged the patient's pain as more intense, disabling, attributed the pain to a lesser extent to psychological factors, considered the clinical situation as more severe, and were more willing to provide the patient instrumental support. We did not confirm our hypothesis 2 about the larger effect of evidence of pathology on pain assessment and management practices towards the lower SES patient. On the contrary, our results showed the opposite pattern regarding pain intensity assessments; pain was indeed perceived as more intense when evidence of pathology was present than absent, but only for the higher SES patient. Moreover, in the presence of evidence of pathology, the high SES patient's pain (overall and during movement) was perceived as more intense that the low SES patient's pain.

\section{Discussion}

This study aimed to experimentally test the effects of patients' socioeconomic status (SES) on nurses' pain assessment and management practices and to investigate whether patient SES moderated the effects of relevant clinical cues on pain assessment and management practices, namely, patient distress and evidence of pathology.

Our first hypothesis that lower SES patient's pain would be underassessed and undertreated as compared to the higher SES patient's pain was partially confirmed. In terms of 

https://doi.org/10.1093/pm/pnz148)

pain assessment, as expected, nurses judged the pain of the lower SES patient as slightly less intense (both overall pain and pain during movement) as compared to the pain of the higher SES patient. Despite the small to medium effect sizes, this pattern was consistent across the two studies and is in line with previous research exploring racial/ethnic disparities (used as a proxy of SES), which showed that health care professionals underestimated the pain of members of ethnic minority groups $(10,34)$. Similar results were also found among laypeople, who attributed less pain to those perceived as having a lower social status (35).

The reason as to why low SES individuals seem to be perceived as less sensitive to pain might be associated with perceived life hardship. Indeed, a few studies conducted in the United States of America have shown that because black people are often perceived as living a less privileged life full of hardship, they are also perceived as more robust, tough and, consequently, less sensitive to pain $(1,35)$. Another possible mechanism accounting for the SES effect on pain intensity assessments may be the process of dehumanization, i.e., perceiving others as less than human (36). Indeed, socioeconomically disadvantaged people are often denied characteristics that distinguish humans from animals (37), which may account for perceiving them as more pain tolerant (38). The role of perceived hardship and animalistic dehumanization $(17,18)$ on SES biases in health-care professionals' pain assessment and management practices is, however, yet to be investigated.

Next to the effects of patient SES on pain intensity assessments, hypothesis 1 was also confirmed for psychological attributions to pain; also, results seem to suggest a small SES effect over pain credibility but only in the presence of distress cues. As compared to the high SES patient's pain, the low SES patient's pain was slightly more attributed to psychological causes. These results are consistent with previous research showing that the activation of common-sense models of somatization (i.e., the belief that physical symptoms result from the 

https://doi.org/10.1093/pm/pnz148)

somatization of stress) is more frequent when interpreting women's pain (3) but also the symptoms of low social status individuals $(1,38)$. Taking this evidence together, it is not surprising that the woman of low SES had her pain slightly more attributed to psychological factors than the woman of high SES.

The reason as to why, in the presence of distress cues, the low SES woman's pain seemed to be perceived as less credible than the high SES woman's pain is less clear. One could argue that it could be corollary to the SES effect on psychological attributions, as the latter are sometimes associated with lower pain credibility (17). However, in both studies, psychological attributions were not significantly correlated with pain credibility. It is possible that the perception of low SES pain patients as being needy and "drug-seekers" (8) may have contributed to this trend. However, more research is needed to confirm this tendency and to examine the contents of stereotypical representations of low SES vs. high SES pain patients as to increase our ability to account for SES disparities in pain care.

In terms of nurses' intentions of pain management, our hypotheses were not confirmed. Patient SES did not have a significant effect on nurses' intentions of offering emotional or instrumental support nor on the Manchester Triage. This pattern of findings is in line with previous studies on social disparities in pain care, where biases could indeed be found on pain assessments but not on pain management practices $(3,39)$. This pattern may eventually be understood as a result of a disconnection between implicit biases and actual behaviour. In fact, as compared to pain management intentions, pain assessments may be more influenced by implicit biases while treatment decisions may more influenced by reflective and intentional cognitive processes and, consequently, more influenced by social desirability and/or a norm of health-care equity. Also, the influence of social desirability and/or health-care equity norm may be particularly salient for management practices like offering emotional and instrumental 

https://doi.org/10.1093/pm/pnz148)

support to a pain patient. The absence of SES biases in the Manchester Triage results may also have been accounted for by the fact that most of our participants did not have any experience in working in Emergency Departments, where this system is generally implemented.

In our second hypothesis we expected that high SES would buffer the detrimental effects of the presence of distress cues and absence of evidence of pathology on nurses' pain assessment and management practices. This hypothesis, however, was only confirmed for distress cues; indeed, only the pain credibility of the low SES woman was slightly hindered by the presence of distress. These results partially extend previous findings supporting the negative effects of distress cues on pain assessments, in general (17) and assessments of women's pain, in particular $(3,40)$. The novelty of these findings lies in the fact that they point to the protective role of high SES on the detrimental effects of distress on women's pain assessment. More specifically, they may be suggesting that high SES women's distress is less likely to activate common-sense models of somatization, which often lead to lower pain credibility judgements $(3,40)$. This hypothesis, however, is yet to be directly tested.

As for evidence of pathology, our results, were contrary to our hypothesis. When evidence of pathology was present nurses rated the pain of the high SES patient as a bit more intense than when evidence of pathology was absent. However, low SES patients' pain intensity (both during movement and overall) was equally assessed, regardless of the absence or presence of evidence of pathology. The reason as to why this pattern of findings is inconsistent with our predictions is harder to account for as we have yet little knowledge on the specific processes underlying nurses' pain assessments.

\section{Limitations, future directions for research, and implications}



https://doi.org/10.1093/pm/pnz148)

As any other piece of research, our studies present some limitations, which point to directions for future research. Despite the usefulness of experimental studies with written vignettes to test causal relationships, they represent natural clinic scenarios in a partial and (over)simplified way, which can raise some concerns regarding studies' ecological and construct validity. Although the use of a video of a real patient while she was performing an induced pain activity may have contributed to increase the studies' ecological validity, the generalization of findings to real clinical contexts and to other kinds of SES manipulations (e.g., other types of professions) should be done with caution. Indeed, on the one hand, some of our effect sizes were small, raising questions regarding their potential clinical significance in real contexts. On the other hand, we have manipulated SES by exclusively manipulating patient profession/education, while keeping constant important cues for social class categorization (e.g., physical appearance, posture, demeanor) (41), which may have partially accounted for the small effect sizes. Given the complexities of social class recognition and categorization processes (41), future studies should further examine classism effects on pain assessment and management practices in naturalistic settings.

It is important to note that our vignettes represented a patient displaying moderate levels of pain behaviors, which may have also hindered the detection of SES biases. Indeed, as previous studies have shown (17), higher levels of pain intensity, by increasing the ambiguity of the clinical situation may increase the likelihood of assessment biases. Future studies should explore the moderating role of pain intensity on SES biases in pain assessment and treatment.

Also, we do not know whether the same pattern of results could be found not only for male to male assessments but also to sex-discordant assessments (i.e., a male nurse assessing a female patient or a female nurse assessing a male patient). Indeed, previous evidence has shown that patients' and health care professionals' sex $(3,42,43)$ influence pain assessment 

https://doi.org/10.1093/pm/pnz148)

and management practices. For this reason, future studies should explore if this pattern of findings emerges when male patients and male health care professionals are also included. Also, only nurses and nursing students were included, which limits our conclusions regarding pain treatment decisions. Although a few previous studies found no effects of patient SES on physicians' pain assessment and management practices $(12,13)$, some qualitative findings have indeed suggested that decisions regarding pain pharmacological treatments may be influenced by patients' SES (8). As such, more future studies should include physicians and experimentally test the effect of patient SES on doctors' treatment decisions.

It should also be noted that our findings are to some extent descriptive and do not tap into the cognitive and/or motivational mediating processes that may account for SES biases in pain care. Beyond examining if such biases exist, researchers should explore which mechanisms may underlie them (e.g., hardship, dehumanization, empathy) along with the stereotypical meanings associated to pain experiences of people with different SES. The identification of such stereotype contents and mediating mechanisms is of high importance for developing interventions targeting SES biases in pain care.

Despite these limitations, this study bears important implications mostly for research, but also, and eventually, for clinical practice. Although much research has been conducted on gender (5) and race biases in pain care (2), little attention has been paid to the role of social class biases in pain assessment and management practices. Being patient SES a close proxy of social class, this paper is, to the best of our knowledge, one of a few to provide experimental evidence on the presence of classism in pain assessments. It also points to the potential buffering role of SES against the detrimental effect of certain clinical cues on pain assessments. Overall, these findings mainly contribute to raise the need to further investigate the role of SES/social class on pain care and its underlying meanings and processes. Raising awareness 
https://doi.org/10.1093/pm/pnz148)

of the potential detrimental influence of classism on pain assessment may contribute to the development of more accurate clinical practices. Indeed, it is only upon such knowledge that empirically-based interventions may in the future be developed to promote social equity in pain care. This paper is a stepping stone in that direction.

\section{Conflict of Interest Statement}

The authors declare that they have no conflict of interest.

\section{References}

1 - Hoffman KM, Trawalter S, Axt JR, Oliver MN. Racial bias in pain assessment and treatment recommendations, and false beliefs about biological differences between blacks and whites. Proc Natl Acad Sci 2016;113:4296-4301.

2 - Tait RC, Chibnall JT. Racial/ethnic disparities in the assessment and treatment of pain: psychosocial perspectives. Am Psychol 2014; 69:131-141.

3 - Bernardes SF, Lima ML. A contextual approach on sex-related biases in pain judgements: the moderator effects of evidence of pathology and patients' distress cues on nurses' judgements of chronic low-back pain. Psychol Health 2011;26:1642-1658. Doi: doi.org/10.1080/08870446.2011.553680

4 - Bernardes SF, Lima ML. On the contextual nature of sex-related biases in pain judgments: The effects of pain duration, patient's distress and judge's sex. European J Pain 2011;15:950957. 

https://doi.org/10.1093/pm/pnz148)

5 - Samulovitz A, Gremyr I, Eriksson E, Hensing G. "Brave men" and "Emotional women”: a theory-guided review on gender bias in health-care and gendered norms towards patients with chronic pain. Pain Res Manag 2018: ID6358624. Doi: 10.1155/2018/6358624.

6 - Lott B. Cognitive and behavioral distancing from the poor. Am Psychol 2002;57:100-110. Doi: 10.1037/0003-066X.57.2.100

7 - Lott B. The social psychology of class and classism. Am Psychol, 2012;67:650-658. Doi: $10.1037 / \mathrm{a} 0029369$

8 - Hollingshead NA, Matthias MS, Bair M, Hirsh AT. Healthcare providers' perceptions of socioeconomically disadvantaged patients with chronic pain: a qualitative investigation. $J$ Health Dispar Res Pract 2016;9:35-44

9 - Pettit KE, Turner JS, Kindrat JK, Blythe GJ, Hasty GE, Perkins AJ, ... Cooper DD. Effect of Socioeconomic Status Bias on Medical Student-Patient Interactions Using an Emergency Medicine Simulation. AEM Educ Train 2017;1:126-131. Doi: 10.1002/aet2.10022

10 - Joynt M, Train MK, Robbins BW, Halterman JS, Caiola E, Fortuna RJ. The impact of neighborhood socioeconomic status and race on the prescribing of opioids in emergency departments throughout the united states. J Gen Intern Med 2013;28:1604-1610. Doi: doi.org/10.1007/s11606-013-2516-z

11 - Haider AH, Sexton J, Sriram N, Cooper LA, Efron DT, Swoboda S, Villegas CV, Haut ER, Bonds M, Pronovost PJ, Lipsett PA, Freischlag JA, Cornwell EE. Association of unconscious race and social class bias with vignette-based clinical assessments by medical students. JAMA 2011;306:942-951. Doi: doi.org/10.1001/jama.2011.1248 

https://doi.org/10.1093/pm/pnz148)

12 - Haider AH, Schneider EB, Sriram N, Dossick DS, Scott VK, Swoboda SM, Losonczy L, Haut ER, Efron DT, Pronovost PJ, Freischlag JA, Lipsett PA, Cornwell EE, MacKenzie EJ, Cooper LA. Unconscious race and class bias: its association with decision making by trauma and acute care surgeons. J Trauma Acute Care Surg 2014;77:409-416. Doi: 10.1097/TA.0000000000000392

13 - Haider AH, Schneider EB, Sriram N, Scott VK, Swoboda SM, Zogg CK, Dhiman N, Haut ER, Efron DT, Pronovost PJ, Freischlag JA, Lipsett PA, Cornwell EE, MacKenzie EJ, Cooper LA. Unconscious race and class biases among registered nurses: vignette-based study using implicit association testing. $J$ Am Coll Surg 2015;220:1077-1086. Doi: 10.1016/j.jamcollsurg.2015.01.065

14 - Haider AH, Sexton J, Sriram N, Cooper LA, Efron DT, Swoboda S, Villegas CV, Haut ER, Bonds M, Pronovost PJ, Lipsett PA, Freischlag JA, Cornwell EE. Association of unconscious race and social class bias with vignette-based clinical assessments by medical students. JAMA 2011;306:942-951. Doi: doi.org/10.1001/jama.2011.1248

15 - Kress HG, Aldington D, Alon E, Coaccioli S, Collett B, Coluzzi F, ... Mangas AC. A holistic approach to chronic pain management that involves all stakeholders: change is needed. Curr Med Res Opin, 2015;31:1743-1754.

16- Twycross A, Quinn R, Leegaard M, Salvetti, M, Gordon D. International Association for the Study of Pain - Curriculum Outline on Pain for Nursing; 2018. Retrived from https://www.iasp-pain.org/Education/CurriculumDetail.aspx?ItemNumber=2052 

https://doi.org/10.1093/pm/pnz148)

17 - Tait RC, Chibnall JT, Kalauokalani D. Provider judgments of patients in pain: seeking symptom certainty. Pain Med 2009;10:11-34. Doi: doi.org/10.1111/j.1526-4637.2008.00527.x

18 - Twigg OC, Byrne DG. The influence of contextual variables on judgments about patients and their pain. Pain Med 2015;16:88-98. Doi: doi.org/10.1111/pme.12587

19 - Melloti RM, Samolsky Dekel BG, Carosi F, Ricchi E, Chiari P, D’Andrea R, Di Nino G. Categories of congruence between inpatient self-reported pain and nurses evaluation. Eur J Pain, 2009;13:992-1000. doi: 10.1016/j.ejpain.2008.11.019.

20 - Samolsky Dekel BG, Gori A, Vasarri A, Sorella MC, Nino G, Melotti RM. Medical evidence influence on inpatients and nurses pain ratings agreement. Pain Res Manag 2016; 9267536.

21 - Lorenzi-Cioldi F. Les représentations des groupes dominants et dominés. Collections et agrégats. Grenoble: PUG, 2002.

22 - Faul F, Erdfelder E, Buchner A, Lang AG. G* Power Version 3.1.7 [computer software]. Germany:Universität Kiel, 2013.

23 - Azevedo LF, Costa-Pereira A, Mendonça L, Dias CC, Castro-Lopes JM. Epidemiology of chronic pain: a population-based nationwide study on its prevalence, characteristics and associated disability in Portugal. $J$ Pain 2012;13:773-783. Doi: doi.org/10.1016/j.jpain.2012.05.012

24 - Azevedo LF, Costa-Pereira A, Mendonça L, Dias CC, Castro-Lopes, JM. The economic impact of chronic pain: a nationwide population-based cost-of-illness study in Portugal. Eur $J$ Health Econ 2016;17:87-98. 

https://doi.org/10.1093/pm/pnz148)

25 - Breivik H, Collett B, Ventafridda V, Cohen R, Gallacher D. Survey of chronic pain in Europe: prevalence, impact on daily life, and treatment. Eur J Pain 2006;10:287-333.

26 - De Ruddere L, Goubert L, Stevens M, Williams ACDC, Crombez G. Discounting pain in the absence of medical evidence is explained by negative evaluation of the patient. Pain 2013;154:669-676. Doi: 10.1016/j.pain.2012.12.018

27 - De Ruddere L, Goubert L, Stevens MAL, Deveugele M, Craig KD, Crombez G. Health care professionals' reactions to patient pain: impact of knowledge about medical evidence and psychosocial influences. J Pain 2014;15:262-270. Doi: doi.org/10.1016/j.jpain.2013.11.002

28 - Marmot M. Status syndrome. Significance 2004;1:150-154. Doi: 10.1111/j.17409713.2004.00058.x

29 - Bernardes S, Costa M, Carvalho H. Engendering pain management practices: the role of physician sex on chronic low-back pain assessment and treatment prescriptions. $J$ Pain 2013;14:931-940. Doi: doi.org/10.1016/j.jpain.2013.03.004

30 - Adler NE, Epel ES, Castellazzo G, Ickovics JR. Relationship of subjective and objective social status with psychological and physiological functioning: preliminary data in healthy white women. Health Psychol 2000;19:586-592.

31 - Dorkin RH, Turk DC, Farrar JT, Haythornthwaite JA, Jensen MP, Kats NP ... Carr DB. Core outcome measures for chronic pain clinical trials: IMMPACT recommendations. Pain; 113:9-19.

32 - Bernardes SF. Sobre a contextualidade dos enviesamentos de sexo nos julgamentos de dor. Lisboa:Fundação Calouste Gulbenkian, 2010. 

https://doi.org/10.1093/pm/pnz148)

33 - Mackway-Jones K, Marsden J, Windle J. Emergency Triage: Manchester Triage Group. John Wiley \& Sons, 2013. Doi: 10.1002/9781118299029

34 - Anderson KO, Green CR, Payne R. Racial and ethnic disparities in pain: causes and consequences of unequal are. $J$ Pain 2009; 10:1187-1204. Doi: doi.org/10.1016/j.jpain.2009.10.002

35 - Trawalter S, Hoffman KM, Waytz A. Racial bias in perceptions of others' pain. PloS One 2012;7:e48546.

36 - Haslam N. Dehumanization: an integrative review. Pers Soc Psychol Rev 2006;10:252264. Doi: doi.org/10.1207/s15327957pspr1003_4

37 - Loughnan S, Haslam N, Sutton RM, Spencer B. Dehumanization and social class: Animality in the stereotypes of "white trash," "chavs," and "bogans". Soc Psychol 2014;45:5461.

38 - Lammers J, Stapel DA. Power increases dehumanization. Group Process Intergroup Relat 2011;14:113-126. Doi: doi.org/10.1177/1368430210370042

39 - Uri O, Elias S, Behrbalk E, Halpern P. No gender-related bias in acute musculoskeletal pain management in the emergency department. Emerg Med $J$ 2015;32:149-152. Doi: 10.1136/emermed-2013-202716

40 - Chiaramonte G. R., Friend R. Medical students' and residents' gender bias in the diagnosis, treatment, and interpretation of coronary heart disease symptoms. Health Psychol 2006;25:255-266. Doi: 10.1037/0278-6133.25.3.255 

https://doi.org/10.1093/pm/pnz148)

41 - Kraus MW, Park JW, Tan JJ. Signs of Social Class: The Experience of Economic Inequality in Everyday Life. Perspect Psychol Sci 2017;12:422-435.

42 - Escobar JI, Rubio-Stipec M, Canino G, Karno M. Somatic symptom index (SSI): a new and abridged somatization construct: prevalence and epidemiological correlates in two large community samples. J Nerv Ment Dis 1989;177:140-146.

43 - Hirsh AT, Hollingshead NA, Matthias MS, Bair MJ, Kroenke K. The influence of patient sex, provider sex, and sexist attitudes on pain treatment decisions. J Pain 2014;15:551-559. 